\title{
DIFFUSION COEFFICIENT ESTIMATION DIFFICULTIES AT THE BEGINNING OF DRYING EXPERIMENT
}

\author{
Aivars Aboltins ${ }^{1}$, Tatjana Rubina ${ }^{1}$ Egle Jotautiene ${ }^{2}$ \\ ${ }^{1}$ Latvia University of Agriculture; ${ }^{2}$ Aleksandras Stulginskis University, Lithuania \\ aivars.aboltins@inbox.lv, tatjana.rubina@llu.lv, egle.jotautiene@asu.lt
}

\begin{abstract}
The aim of this paper is to determine the error of the diffusion coefficient of removed moisture applying convection drying of carrot slices. In this study series for diffusion coefficient calculation are applied and the diffusion coefficient error at the beginning of the experiment is investigated. The experiments were carried out with carrot slices of $15 \mathrm{~mm}$ thickness on laboratory conditions. There are compared drying processes by different drying temperatures with the purpose to investigate the temperature effect on the diffusion coefficient changes. Using the experimental data the theoretical diffusion coefficient was calculated using iterative methods with small drying time. The research shows that one should be careful when using the first term of solution of the Fick's second law of diffusion, although in practice only the first term of the series is often applied. The results of this research showed that the error of the diffusion coefficient occured due to several members of series at small times. The theoretical results are useful for description and modelling of the drying process with the time dependent diffusion coefficient for carrot slices and pieces on two- and threedimensional case. The calculated parameters can be used for further research work and for improvement of the whole drying process.
\end{abstract}

Keywords: drying, diffusion coefficient, carrot.

\section{Introduction}

Drying of agricultural products is one of the main goals of preservation, transportation and commerce. The drying process reduces the moisture content in materials. It helps minimize microbiological activity in products during storage time and increases the product stability and persistence.

One of the important aspects for understanding the drying process is to process mathematical modelling. The sgricultural production drying process is a complex process. To determine the drying rate and optimized drying parameters a suitable kinetic model is needed. There are many biological material drying kinetic models [1]. Most popular are the models of thin layer drying. These models allow many physical variables considered as constants and thus simplify the mathematical model of drying [2].

On average, each of these models is based on the application of various mathematical expressions to describe the experimental data without the required parameter explanation and application description. Often in these cases the main criterion is the $\mathrm{R}^{2}$ value without taking into account the measurement errors.

On the other hand an important indicator of the drying process is the diffusion coefficient. This is particularly important for product drying, which cannot be regarded as a thin layer. Knowing it we are better able to simulate numerically the body drying. The drying coefficient and diffusion coefficient are connected with the solution of the Fick's second law of diffusion [3; 4]. However, in practice only the first term of the series is often applied and only for a long drying period [5].

The purpose of this article is to clarify what error is made using the first term of series and compare with literature used expressions, as well as using the experimental data to determine the diffusion coefficient of carrots dependent on the moisture concentration.

\section{Materials and methods}

The research object is carrot slices. Before the experiment execution carrots were washed under running water, wiped and cut into slices with $15 \mathrm{~mm}$ thickness. The carrots were not peeled and blanched. To obtain the experimental data the carrot samples were dried at three constant temperatures: $60^{\circ} \mathrm{C}, 80^{\circ} \mathrm{C}$ and $90^{\circ} \mathrm{C}$. Each sample contains carrot slices that were imposed in a single layer on an individual tray with a perforated base.

The drying chamber Memmert was used for the drying experiments with accuracy of temperature control $\pm 0.3{ }^{\circ} \mathrm{C}$. The drying chamber is a vertical type camera, in which the air flows upwards through 
the sample trays that provide the access of hot air to the carrot slices on both sides. During the drying process free ventilation was performed. Each tray was weighed before inserting it in the dryer.

A laboratory balance Kern EW 1500-2M was used for weighing, with measurement accuracy $\pm 0.01 \mathrm{~g}$. The samples were regularly weighed during the experiment and the values were recorded regularly to determine the mass changes on the drying time at certain temperature.

If $M_{t}$ denotes the amount of diffusing moisture, which has come out from the material at time $t$, and $M_{\infty}$ the corresponding quantity after the infinite time, then [3]:

$$
\frac{M(t)}{M_{\infty}}=1-\sum_{n=0}^{\infty} \frac{8}{(2 n+1)^{2} \pi^{2}} \exp \left(-D \frac{(2 n+1)^{2} \pi^{2} t}{L^{2}}\right),
$$

where $L-$ thickness of carrot slices, $\mathrm{mm}$;

$M(t)$ - removal moisture weight from layer at time moment $t, \mathrm{~g}$;

$M_{\infty}$ - moisture weight after infinite time, g;

$t$ - drying time, $\mathrm{h}$;

$D$ - diffusion coefficient, $\mathrm{mm}^{2} \cdot \mathrm{h}^{-1}$.

Taking the first term of the series expression (1) becomes

$$
\frac{8}{\pi^{2}} \cdot \exp \left(-D \frac{\pi^{2} t}{L^{2}}\right)=1-\frac{M_{t}}{M_{\infty}}
$$

The right-hand side of the equation (2) is known (experimental data at time $t=t_{i}$ ). Using formula (2) it is possible to calculate the diffusion coefficient $D\left(t_{i}\right)$ at each time moment $t_{i}$ using formula:

$$
D\left(t_{i}\right)=-\frac{L^{2}}{\pi^{2} t_{i}} \ln \left(\frac{\pi^{2}}{8}\left(1-\frac{M\left(t_{i}\right)}{M_{\infty}}\right)\right) .
$$

Using more terms of series we get a nonlinear equation that cannot in general be solved analytically. Therefore, the solution of the equation can be approached numerically using iterative methods. In this research we used the bisection or dichotomy method that is based on the property of intervals [6].

\section{Results and discussion}

The carrot drying experiment results were used for estimation of series. The results of the diffusion coefficients in different stages of drying at drying temperatures $60{ }^{\circ} \mathrm{C}$ and $90{ }^{\circ} \mathrm{C}$, and different amounts of terms from series (1) are shown in Table 1 and Table 2.

Diffusion coefficient values $\left(\mathrm{mm}^{2} \cdot \mathrm{h}^{-1}\right)$ at drying temperature $60{ }^{\circ} \mathrm{C}$

Table 1 with different amount of series terms

\begin{tabular}{|c|c|c|c|c|c|}
\hline Time & $1-\frac{\boldsymbol{M}_{t}}{M_{\infty}}$ & $\begin{array}{c}\text { Diffusion } \\
\text { coefficient } \\
\text { using first term } \\
\text { of series, } \boldsymbol{D}_{\mathbf{1}}\left(\boldsymbol{t}_{\boldsymbol{i}}\right)\end{array}$ & $\begin{array}{c}\text { Second term of } \\
\text { series, } \boldsymbol{a}_{\mathbf{2}}\end{array}$ & $\begin{array}{c}\text { Diffusion } \\
\text { coefficient } \\
\text { using first } \mathbf{1 0}^{\text {th }} \\
\text { terms, } \boldsymbol{D}_{\mathbf{1 0}}\left(\boldsymbol{t}_{\boldsymbol{i}}\right)\end{array}$ & $\begin{array}{c}\mathbf{1 1}^{\text {th }} \text { term of } \\
\text { series, } \boldsymbol{a}_{\mathbf{1 1}}\end{array}$ \\
\hline 0.5 & 0.990 & -9.131 & $1.39 \mathrm{E}-01$ & -0.054 & $2.74 \mathrm{E}-03$ \\
\hline 1.0 & 0.977 & -4.248 & $1.31 \mathrm{E}-01$ & 0.009 & $1.42 \mathrm{E}-03$ \\
\hline 1.5 & 0.957 & -2.518 & $1.20 \mathrm{E}-01$ & 0.053 & $3.83 \mathrm{E}-04$ \\
\hline 2.0 & 0.940 & -1.692 & $1.11 \mathrm{E}-01$ & 0.078 & $8.79 \mathrm{E}-05$ \\
\hline 2.5 & 0.917 & -1.123 & $9.83 \mathrm{E}-02$ & 0.122 & $4.96 \mathrm{E}-06$ \\
\hline 3.0 & 0.893 & -0.740 & $8.65 \mathrm{E}-02$ & 0.167 & $1.13 \mathrm{E}-07$ \\
\hline 3.5 & 0.872 & -0.479 & $7.65 \mathrm{E}-02$ & 0.205 & $1.69 \mathrm{E}-09$ \\
\hline 4.0 & 0.851 & -0.275 & $6.67 \mathrm{E}-02$ & 0.246 & $9.63 \mathrm{E}-12$ \\
\hline
\end{tabular}


Table 1 (continued)

\begin{tabular}{|c|c|c|c|c|c|}
\hline Time & $1-\frac{M_{t}}{M_{\infty}}$ & $\begin{array}{c}\text { Diffusion } \\
\text { coefficient } \\
\text { using first term } \\
\text { of series, } \boldsymbol{D}_{\mathbf{1}}\left(\boldsymbol{t}_{\boldsymbol{i}}\right)\end{array}$ & $\begin{array}{c}\text { Second term of } \\
\text { series, } \boldsymbol{a}_{\mathbf{2}}\end{array}$ & $\begin{array}{c}\text { Diffusion } \\
\text { coefficient } \\
\text { using first } \mathbf{1 0}^{\text {th }} \\
\text { terms, } \boldsymbol{D}_{\mathbf{1 0}}\left(\boldsymbol{t}_{\boldsymbol{i}}\right)\end{array}$ & $\begin{array}{c}\mathbf{1 1}^{\text {th }} \text { term of } \\
\text { series, } \boldsymbol{a}_{\mathbf{1 1}}\end{array}$ \\
\hline 4.5 & 0.827 & -0.104 & $5.70 \mathrm{E}-02$ & 0.293 & $1.58 \mathrm{E}-14$ \\
\hline 5.0 & 0.808 & 0.012 & $4.97 \mathrm{E}-02$ & 0.324 & $4.36 \mathrm{E}-17$ \\
\hline 5.5 & 0.784 & 0.136 & $4.12 \mathrm{E}-02$ & 0.373 & $1.04 \mathrm{E}-20$ \\
\hline 6.0 & 0.761 & 0.238 & $3.40 \mathrm{E}-02$ & 0.419 & $1.38 \mathrm{E}-24$ \\
\hline 6.5 & 0.738 & 0.329 & $2.75 \mathrm{E}-02$ & 0.467 & $5.84 \mathrm{E}-29$ \\
\hline 7.0 & 0.717 & 0.401 & $2.23 \mathrm{E}-02$ & 0.507 & $2.85 \mathrm{E}-33$ \\
\hline 22.5 & 0.066 & 2.544 & $1.38 \mathrm{E}-11$ & 2.544 & 0.000 \\
\hline 23.0 & 0.043 & 2.918 & $2.79 \mathrm{E}-13$ & 2.918 & 0.000 \\
\hline
\end{tabular}

Diffusion coefficient values $\left(\mathrm{mm}^{2} \cdot \mathrm{h}^{-1}\right)$ at drying temperature $90{ }^{\circ} \mathrm{C}$

Table 2 with different amount of series terms

\begin{tabular}{|c|c|c|c|c|c|}
\hline Time & $1-\frac{M_{t}}{M_{\infty}}$ & $\begin{array}{c}\text { Diffusion } \\
\text { coefficient } \\
\text { using first term } \\
\text { of series, } D_{1}\left(t_{i}\right)\end{array}$ & $\begin{array}{l}\text { Second term of } \\
\text { series, } a_{2}{ }^{*}\end{array}$ & $\begin{array}{c}\text { Diffusion } \\
\text { coefficient } \\
\text { using first } 10^{\text {th }} \\
\text { terms, } D_{10}\left(t_{i}\right)\end{array}$ & $\begin{array}{l}11^{\text {th }} \text { term of of } \\
\text { series, } a_{11}{ }^{*}\end{array}$ \\
\hline 0.5 & 0.981 & -8.681 & $1.3 \mathrm{E}-01$ & -0.005 & $1.7 \mathrm{E}-03$ \\
\hline 1.0 & 0.939 & -3.351 & $1.1 \mathrm{E}-01$ & 0.164 & $7.6 \mathrm{E}-05$ \\
\hline 1.5 & 0.890 & -1.414 & $8.5 \mathrm{E}-02$ & 0.359 & $5.5 \mathrm{E}-08$ \\
\hline 2.0 & 0.838 & -0.379 & $6.1 \mathrm{E}-02$ & 0.580 & $3.3 \mathrm{E}-13$ \\
\hline 2.5 & 0.784 & 0.302 & 4.1E-02 & 0.823 & 9.3E-21 \\
\hline 3.0 & 0.741 & 0.679 & $2.8 \mathrm{E}-02$ & 0.985 & $2.7 \mathrm{E}-28$ \\
\hline 3.5 & 0.690 & 1.052 & $1.7 \mathrm{E}-02$ & 1.215 & 3.4E-39 \\
\hline 4.0 & 0.645 & 1.298 & $1.0 \mathrm{E}-02$ & 1.388 & $4.1 \mathrm{E}-50$ \\
\hline 4.5 & 0.600 & 1.527 & $5.5 \mathrm{E}-03$ & 1.574 & $5.9 \mathrm{E}-63$ \\
\hline 5.0 & 0.550 & 1.769 & $2.6 \mathrm{E}-03$ & 1.791 & $1.0 \mathrm{E}-78$ \\
\hline 5.5 & 0.512 & 1.903 & $1.4 \mathrm{E}-03$ & 1.914 & $6.4 \mathrm{E}-92$ \\
\hline 6.0 & 0.471 & 2.065 & $6.7 \mathrm{E}-04$ & 2.071 & 7.6E-108 \\
\hline 6.5 & 0.433 & 2.199 & $3.2 \mathrm{E}-04$ & 2.201 & $1.2 \mathrm{E}-123$ \\
\hline
\end{tabular}

It is seen that the rows (1) $2^{\text {nd }}$ term $a_{2}$, which is not taken into account, is large compared to the $11^{\text {th }}$ term. This is a significant impact on the residual of series, which is not taken into account in determining the value of $D$ (Table 1 and Table 2). The result shows that using of the first term of series does not depend on the drying time, but on the drying product moisture (Fig. 3).

In this research we examine formula (2) taking one and ten terms of sum in order to determine the diffusion coefficient changes during the drying experiment. In Fig. 1 the diffusion coefficient values are shown depending on the drying time that was calculated by formula (1): $F_{1}$ - taking one term (3) and $F_{2}$ - using ten terms of sum (1). Fig. 1 shows the processed experimental data for the carrot samples with $15 \mathrm{~mm}$ thickness at two drying temperatures $60^{\circ} \mathrm{C}$ and $90{ }^{\circ} \mathrm{C}$. As it can be seen, these values differ noticeably. The values acquired by formula $F_{1}$ contain big error at small experiment times. 
a)

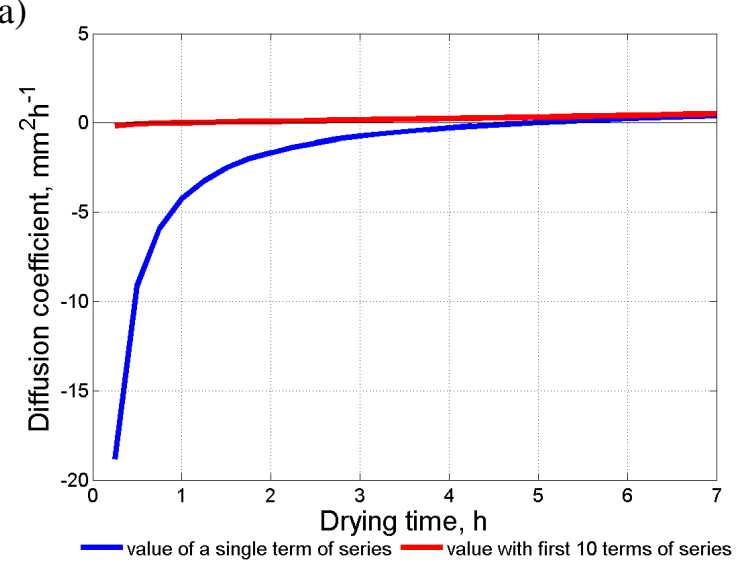

b)

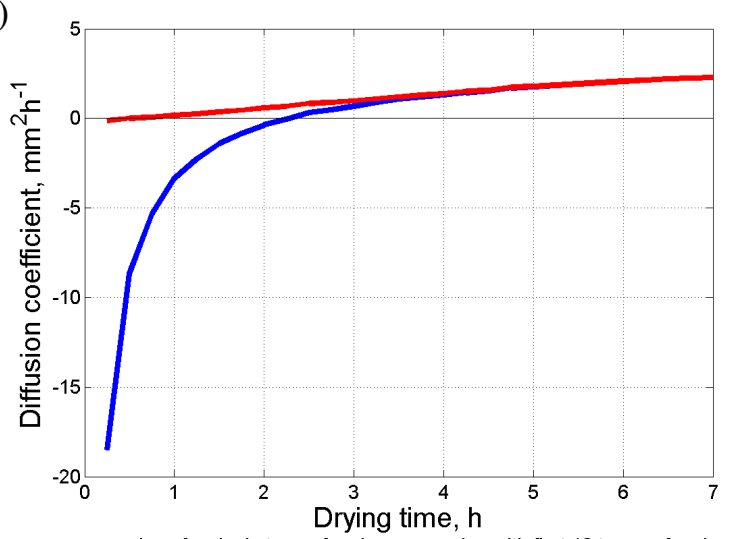

Fig. 1. Diffusion coefficient dependence on the drying time at temperature: $\mathrm{a}-60^{\circ} \mathrm{C} ; \mathrm{b}-90^{\circ} \mathrm{C}$

Assessing the results of the formula $F_{1}$ with the first series term it can be seen that the coefficient values increase at the logarithmic law and the acquired results do not comply with the theory. In order to verify the formula (1), the decision was made to evaluate the diffusion coefficient using the first ten terms of series to determine their impact on the final coefficient value. At the beginning of the drying experiment many beside processes take place in the product till moisture begins to release. It can be a major cause of errors, which appear at the beginning of the experiment and influence the diffusion coefficient value calculated using only the first term (3) of series. In Fig. 1 it can be seen that the diffusion coefficient values calculated using one (3) and the first ten terms of series (1) differ noticeably. But this difference decreases during the drying experiment.

It was concluded that one series term cannot be used for calculation of the diffusion coefficient. For this reason some authors prefer to use a simplified formula (4) for the diffusion coefficient calculation at each time moment $t_{i}[7]$ :

$$
D\left(t_{i}\right)=\frac{K\left(t_{i}\right) L^{2}}{\pi^{2}},
$$

where $L-$ thickness of carrot slices, $\mathrm{mm}$,

$K\left(t_{i}\right)$ - drying coefficient at each time moment $t_{i}, \mathrm{~h}^{-1}$.

In this study, we do not take into account shrinkage of the sample during the drying process.

a)

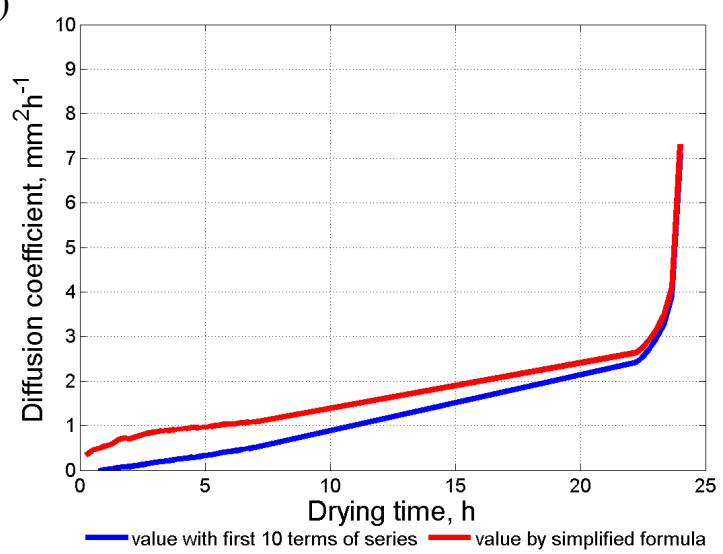

b)

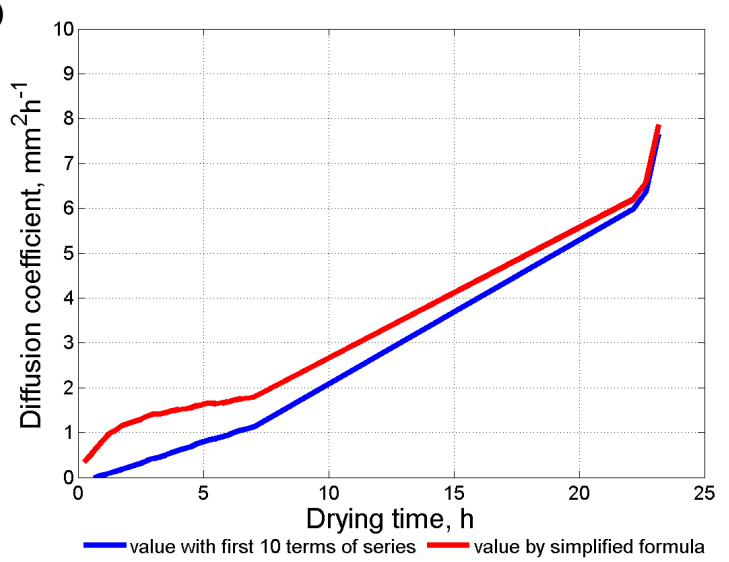

Fig. 2. Diffusion coefficient comparison at different temperatures: $\mathrm{a}-60^{\circ} \mathrm{C} ; \mathrm{b}-80^{\circ} \mathrm{C}$

Fig. 2 shows the comparison of the diffusion coefficient values that were calculated by the simplified formula and formula with 10 terms of series. It can be concluded that the diffusion coefficient values differ slightly and exhibit the same low changes of values. 
a)

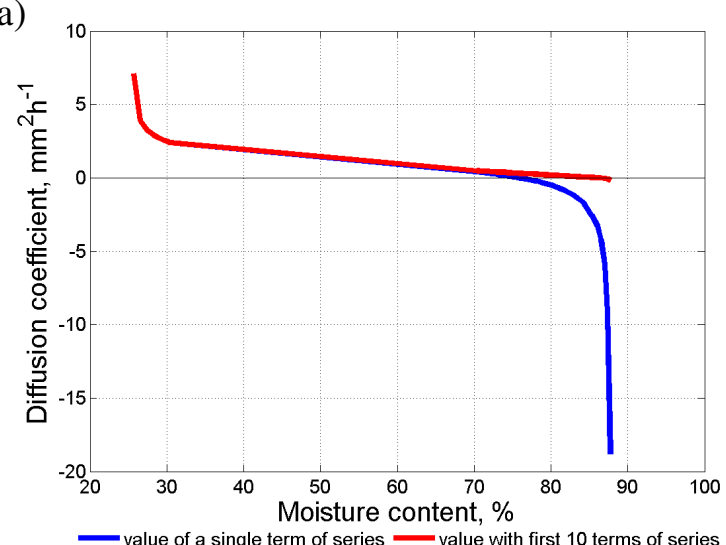

b)

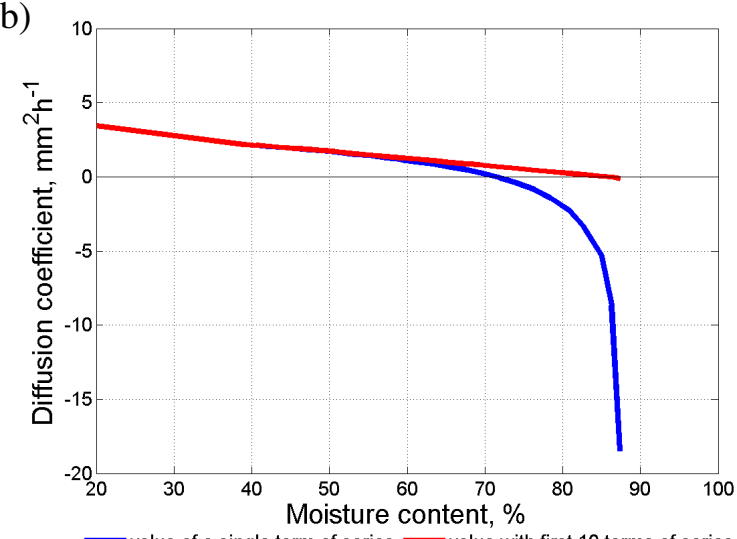

Fig. 3. Diffusion coefficient dependence on the moisture content at different temperatures: $\mathrm{a}-60{ }^{\circ} \mathrm{C} ; \mathrm{b}-90^{\circ} \mathrm{C}$

In Fig. 3 and Fig. 4 the diffusion coefficient dependence on the moisture content is shown taken from the experimental data. Decreasing the moisture concentration the diffusion coefficient increases. At the beginning of the experiment and the first seven hours the low dependence is tight linear (Fig. 4) at constant temperature $60^{\circ} \mathrm{C}$. But at the end of the experiment after 20 drying hours the diffusion coefficient increases exponentially low when the moisture content decreases. But at higher drying temperature the diffusion coefficient value changes remain more linear during all drying experiment. At lower drying temperature the diffusion coefficient values are higher when the moisture content decreases.
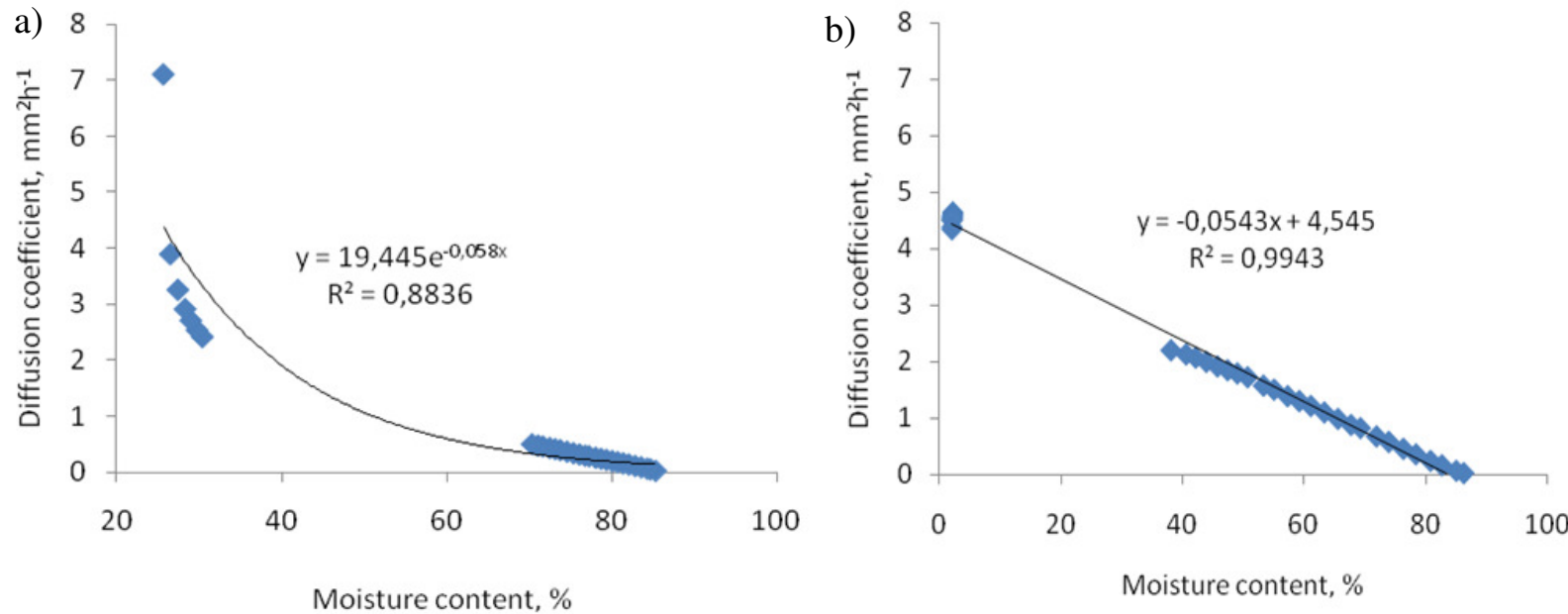

Fig. 4. Diffusion coefficient approximation at different temperatures: $\mathrm{a}-60{ }^{\circ} \mathrm{C} ; \mathrm{b}-90^{\circ} \mathrm{C}$

\section{Conclusions}

1. The study shows that researchers should be careful using the first term of solution of the Fick's second law of diffusion, although in practice only the first term of the series is often applied for the diffusion coefficient calculation.

2. The study result shows that applying only the first term of series in calculation of the diffusion coefficient it does not depend on the drying time, but on the drying product moisture.

3. The value $1-\frac{M_{t}}{M_{\infty}}<0.5$ can be boundary for using of only the first term of series (1) for the diffusion coefficient determination. 
4. For approximate calculation of the diffusion coefficient value a simplified formula can be used. If the study requires highest precision, a series formula with a larger number of terms (at least 15 terms) should be used at small experiment times.

\section{References}

1. Onwude D., Norhashila H., Rimfiel J., Nawi N., Khalina A. Modeling the thin-layer drying of fruits and vegetables: A review, Comprehensive reviews in food science and food safety, Vol. 15, 2016, pp. 599-618.

2. Aboltins A. Theoretical study of material drying coefficient. International Scientific Conference Engineering for Rural Development, Latvia University of Agriculture, Jelgava, Latvia, 2013, pp. 153-158.

3. Crank, J. The mathematics of diffusion, Oxford, Clarendon Press, 1956, 347 pp.

4. Aboltins A., Palabinskis J. Fruit drying process investigation in infrared film dryer. Agronomy research, Vol.14(1), 2016, pp. 5-13.

5. Darvishi H., Khafajeh H., Banakar A., Lofti M. Effect of shape potato chips on drying characteristics. International Journal of Agriculture and Crop Science, Vol.5 (18), 2013, pp. 2009-2018.

6. Atkinson K. An introduction to numerical analysis. Wiley, 1978, 693 pp.

7. Hassini L., S. Azzouz S., Belghith A. Estimation of the moisture diffusion coefficient of potato during hot-air drying. Proceedings of the $14^{\text {th }}$ International Drying Symposium (IDS 2004), São Paulo, Brazil, Vol. B, 22-25 August, 2004, pp. 1488-1495. 